\title{
Surface Settlement Mathematical Model Research in the Process of Shield Tunnel \\ WANG Gui-hua
}

School of Civil Engineering, Baicheng Normal University, Jilin, Baicheng 137000, China

466124747@qq.com

Keywords: Shield tunnel; Subsidence model; Measured values

\begin{abstract}
With the development of economy and technology, the large-diameter tunnel is wildly used. The deformation will be resulted in the process of excavation which will leading to the surface subsidence. Six kinds of mathematical model are put forward in the process of exploring the surface subsidence. For a kind of special geology to study the feasibility of the six kinds of mathematical model. Explore the most appropriate mathematical model for this kind of geological conditions and Play a good guidance and prediction effect role to the engineering practice.
\end{abstract}

\section{Introduction}

With the rapid development of science and technology, people pay more and more attention to the construction of infrastructure, especially the construction of traffic facilities. Tunnel engineering as a kind of important facilities, underground space has experienced a long period development and now in a period of relatively developed. However, there still are many problems in the construction of the tunnel construction and the future operation maintenance aspects. the present development trend of the tunnel toward to extra-long tunnel, large diameter. Our country has rich experience in the construction of tunnel, most part of which are used in the water and gas conveyance tunnel. Many tunnel is crossing the poor geological environment, and even across the rivers and lakes [1]. As the shield technology applied in tunnel engineering, the researchers at home and abroad have a lot of research on the surface of the shield excavation and surface subsidence technology based on the numerical simulation method and model simulation research method. the basic principle of shield tunnel construction is to use a certain shape steel components along designed axis to excavate soil. Steel components form a shield tunnel and the hole in which is protected ty the shield itself. In the meanwhile, other auxiliary measures are need to support hole, and the commonly used supporting method has natural support, mechanical support, compressed air is supported, mud, earth pressure balance. After the study of a lot of subsidence data summary, Peck proposed the surface subsidence trough is the approximate normal distribution curve. Peck believes that formation of ground loss is a major cause lead to ground movement and it can deduce the settling tank volume equal to the volume of formation damage assuming the surface subsidence is under undrained conditions.

\section{Strata Loss and the Factors}

Classification of Strata Loss. Common stratum losses include three categories [2]. The first kind of strata damage is called a normal strata damage. The characteristics of this kind of strata damage is engineer and workers in the construction process design and operations are in accordance with relevant articles of association, able to finish the work very specification, no big mistakes, because of some man-made factors cause some inevitable formation damage. For this kind of strata loss can be control in a certain range by certain measures. The second type is called abnormal strata loss, which is caused by some mistakes happed in the worker operation process. The third kind stratum losses are caused by some disasters, which is due to the unstable soil collapsed in the process of tunnel excavation.

Cause for Strata Loss. The influencing factors of strata subsidence mainly has the following several aspects. 
Embedment Depth. The embedment depth of the tunnel will affect the formation of subsidence and the scope of influenced by the strata subsidence [3]. For showing the relationship, the formula proposed by Atewell commonly used.

$$
\frac{i}{R}=k\left(\frac{h}{2 R}\right)^{n}
$$

Where, $i$ represents the distance from tunnel central axis to inflection point of surface subsidence, $h$ is embedment depth of the tunnel, $R$ is the radius of construction tunnel, $k$ is constant which is stratigraphic correlation coefficient, $n$ is constant related to construction factors.

Size of Tunnel. The specific relationship is the greater radius of excavation tunnel lead the greater the surface subsidence [4] and the both relationship is directly proportional.

Stratigraphic Conditions. Some external factors can affect the surface subsidence different, such as the excavation tunnel region upper covered soil characteristics, cover thickness, geological conditions, hydrologic conditions, the initial stress, physical parameters and so on.

Under Surface Water Content. Shield excavation technology is underground construction, so, before excavation groundwater treatment work need to deal in some more area to reduce the content of groundwater. In the process, different ways and different amount of groundwater will result in different surface subsidence.

Soil Lateral Pressure Coefficient. The calculation method for the lateral pressure coefficient are as follows [5].

$$
N_{t}=\frac{F_{K}}{F_{Y}}
$$

Where, $F_{K}$ is the horizontal supporting force excavation surface subjected, $F y$ is the primary lateral force inside the excavation.

If the value of lateral pressure coefficient within the range of 0 to 1 , supporting force of lateral pressure be less than the original and the surface will product subsidence. If the value of lateral pressure coefficient greater than 1 , supporting force of lateral pressure be greater than the original and the surface will uplift when excavation.

\section{Simulation Mathematical Model of Surface Subsidence}

For the surface subsidence of shield tunnel some mathematical model can applied, so the following were analyzed respectively.

Hyperbolic Equation.

$$
S_{\max }=\frac{t}{a+b t}
$$

Where, $S_{\max }$ represents maximum surface subsidence, $t$ represents time, $a$ and $b$ represents Hyperbolic constant and $a \in(0.0534,0.2934), b \in\left(\frac{1}{85}, \frac{1}{35}\right)$. Take the limit of $\mathrm{t}$ in the last-written denominator.

$$
\lim S_{\max }=\lim \frac{t}{a+b t}=\frac{1}{b}
$$

The surface subsidence is easily observed after a period time shield tunneling excavation. So, it can easily get the value of $a$ and $b$. On that basis, specific value of surface subsidence in different time can be obtained.

But this formula assume instantaneous settlement is zero and calculated settlement calculation value by the general formula is greater than the observed values.

Modified Hyperbolic Equation.

$$
S(t)=\frac{a+b t}{c+d t}
$$


Where, $S_{t}$ represents the upper tunnel subsidence at $t$ time, $a, b, c, d$ all is undetermined coefficients which can be identified according the surface subsidence monitoring values of four different time. This equation is put forward by according the shortage of the hyperbolic. Modified hyperbola has the characteristics of the general hyperbolay, such as monotonicity, boundedness.

Engineering practice shows that modified hyperbolic formula can accurately predict the surface subsidence and can well describe the surface settlement changing with the time [6].

\section{Poisson Curve Model.}

$$
S(t)=\frac{L}{1+a \exp (-b t)}
$$

Where, $L$ is the final settlement, $a$ and $b$ are constant which are greater than zero.

$\boldsymbol{S}$ type Growth Curve. $S$ type curve is applied a lot in natural economy and social life, and can well predict things start stage, growth stage, mature stage which will provide basis for us to estimates its law of development. $S$ type curve consists of the following four types of curves and the four types curve are listed below.

Gompertz model:

$$
S(t)=L \exp \left(-a e^{-b t}\right)
$$

Weibull model:

$$
S(t)=L-a e^{-b t}
$$

Deng Ying model:

$$
S(t)=\frac{L}{1+a \exp \left(-b t^{\tau}\right)}
$$

Mmrgan-mercer-Flodin medel:

$$
S(t)=\frac{a b+L t^{\tau}}{b+t^{\tau}}
$$

Where, $L, a, b, t$ is consistent with the meaning of the poisson curve.

Verhulst Model. Shield caused land subsidence includes two aspects. The first is caused by the construction in the process of soil loss. The second is secondary consolidation due to soil consolidation and secondary consolidation and this part of the settlement will exist for a long time [7].

$$
S(t)=\frac{L}{1+\left(\frac{L}{S_{0}}-1\right) \exp \left(-a\left(T-T_{0}\right)\right)}
$$

Where, $S_{0}$ and $T_{0}$ is the initial settlement and time.

\section{Logarithmic Curve Model.}

$$
S(t)=S_{\max }\left(1-e^{-a t}\right)
$$

Where, $S_{\max }$ represents final surface subsidence, $a$ is constant which can be get. In the process of this formula application, Calculate the unknown coefficients a and $S_{\max }$ according the first measured law of surface settlement changing with the time [8].

\section{Comparing and Analysis of Six Model with Actual Monitoring}

Comparison between Measured and Simulated Values. Through an engineering example to simulating the above model and get more intuitive data comparison. Engineering example is from Qingdao subway line 2. Geological condition is cohesive soil. Tunnel is composed of two tunnels and the data is from the first tunnel. The measured surface subsidence values based on engineering practice and calculation values based on six kinds of surface subsidence model (Hyperbolic model, Modified hyperbola, Poisson curve model, S type growth curve, Verhulst model, Logarithmic curve model) shows as Table 1.

Six Kinds Mathematical Models Analysis. Hyperbolic Model. Through the analysis can learn that, in the 200 days before starting, the difference between surface subsidence and the actual 
observed value is bigger, 200 days after the difference is narrowing and two curve is consistent, settlement can be precisely predicted after 100 days of long-term.

Table 1 Six kinds of settlement model comparing with the actual settlement amount

\begin{tabular}{|c|c|c|c|c|c|c|c|c|c|c|c|}
\hline Time (day) & 0 & 50 & 100 & 150 & 200 & 250 & 300 & 350 & 400 & 450 & 500 \\
\hline $\begin{array}{l}\text { measured } \\
\text { values } \\
(\mathrm{mm})\end{array}$ & 21.7 & 63.7 & 87.3 & 96.5 & 107.4 & 157.8 & 123.6 & 125.8 & 121.4 & 128.9 & 130.7 \\
\hline $\begin{array}{c}\text { Hyperbolic } \\
\text { model } \\
(\mathrm{mm})\end{array}$ & 5.8 & 53,9 & 86.9 & 94.3 & 105.4 & 148.0 & 120.2 & 124.7 & 125.5 & 127.9 & 132.8 \\
\hline $\begin{array}{l}\text { Modified } \\
\text { hyperbolic } \\
\text { Model } \\
(\mathrm{mm})\end{array}$ & 70.2 & 76.3 & 86.9 & 91.7 & 96.9 & 103.6 & 109.7 & 113.2 & 119.8 & 120.0 & 121.4 \\
\hline $\begin{array}{l}\text { Poisson } \\
\text { curve } \\
\text { model } \\
(\mathrm{mm})\end{array}$ & 37.4 & 85.7 & 113.2 & 129.8 & 130.5 & 130.6 & 130.6 & 130.7 & 130.8 & 130.7 & 130.8 \\
\hline $\begin{array}{l}S \text { type } \\
\text { growth } \\
\text { curve } \\
(\mathrm{mm})\end{array}$ & 3.2 & 42.4 & 85.6 & 94.6 & 100.0 & 100.2 & 100.5 & 100.5 & 100.5 & 100.5 & 100.5 \\
\hline $\begin{array}{l}\text { Verhulst } \\
\text { model } \\
(\mathrm{mm})\end{array}$ & 3.5 & 54.6 & 87.6 & 109.7 & 116.5 & 123.7 & 127.5 & 130.6 & 131.7 & 131.9 & 131.9 \\
\hline $\begin{array}{l}\text { Logarithmi } \\
\text { c curve } \\
\text { model } \\
(\mathrm{mm}) \\
\end{array}$ & 23.6 & 52.8 & 80.1 & 99.5 & 110.5 & 116.7 & 123.6 & 125.8 & 126.6 & 129.9 & 130.7 \\
\hline
\end{tabular}

Modified Hyperbolic Model. Using modified hyperbola model to predict the surface subsidence can learn that, surface subsidence is more accurate than hyperbola model predicted, so modified hyperbola model applied in the engineering practice more widely.

Poisson Curve Model. The model has the very good adaptability and can be applied to most of the engineering practice.

S Type Growth Curve (Gompertz Model). Gompertz model is a kind of S description curve in the development of things, and can be clearly describe things in the process of development. The final formula of concrete form.

$$
S(t)=L \exp \left[-a e^{-b t}\right]=102.4 \exp \left[-3.673 e^{-0.0029 t}\right]
$$

It can observe that, before starting test settlement of 70 days or so, The curve of the Gompertz model consistent not well with the actual observed surface settlement. But after 70 days, the comparing shows good agreement with each other, so, So the Gompertz model formula can predict long-term surface settlement. It is not very accurate sometimes in the prediction of surface subsidence. Using this formula should pay attention to its own curve form are consistent with the settlement form.

Verhulst Model. Found four appropriate, reasonable point in known measured surface subsidence, then plug in formula to calculate the unknown coefficient of the value $a, b, r, L$. Then other arbitrary point on the surface subsidence value can be obtained. From the analysis of error can learn that, Verhulst model formula of settlement curve was consistent with actual situation.

Logarithmic Curve Model. From the error analysis, it can learn that settlement curve of logarithmic curve model formula consistent well with the actual situation. It is a good way to predict the surface subsidence.

\section{Conclusion}

This article systematically expounds the process of surface subsidence and the deformation mechanism of produce are analyzed. Through the instance analysis and checking calculation of the 
above six model can get the following conclusion. For hyperbolic model, the gap of the surface subsidence and the actual observed value is bigger before the 200 days start. The gap is narrowing and two curve is consistent after 200 days. The accuracy of Modified hyperbola model is more accurate than surface subsidence value calculated by hyperbolic model. So modified hyperbola model widely applied in the engineering practice. Poisson curve model has good adaptability and can be applied to most of the engineering practice. The curve formed by Gompertz model formula consistent not well with the actual observed the surface settlement curve. They can basically good matches together after 70 days. So, Gompertz model formula can predict long-term surface settlement. So, choosing models to use to should according its characteristics.

\section{References}

[1] Da-jun ZHANG Summary of surface subsidence control technology in the subway construction. [J]. Sichuan building materials 2007(4):59-56.

[2] Jun ZHANG. Further study about the stratum loss rate [J]. Journal of rock mechanics and engineering 2007,24(Supplement 2).

[3] Shi-han QUE. The effect of buried city subway tunnel on stratum deformation and its rational embedment depth determining research [D]. Beijing Jiaotong University, 2010.

[4] Yu Yong-li, Luo Xiao-juan, Wang Yong-jun. Influence factors of ground settlement triggered by shield tunneling in the Beijing area[J]. Journal of Geological Hazards and Environment Preservation, 2012, (01): 21-24.

[5] Jun-yiing LIANG. The soil lateral pressure coefficient test and influence analysis of internal force on shield lining segments[D]. Beijing Jiaotong University, 2011.

[6] Jun-bao WANG, Xin-rong LIU, Peng LI et al. The application of MMF in goaf ground subsidence prediction[J]. Journal of coal, 2012,(03):411-415.

[7] Yu-ping CAO. Relationship of secondary consolidation coefficient of saturated cohesive soil with water content[J]. China harbour building, ,2007,(03):21-23.

[8] Ai-feng YIN, Yu-hai WANG. Soft soil roadbed settlement prediction research based on the hyperbolic model [J]. Jiangsu building, 2012(5): 69-72 